of the celestial equator for which reliable trigonometrical parallaxes, that is, not less than $0.01^{\prime \prime}$, were available, and tangential and radial velocities were corrected for a solar motion component of $20 \mathrm{~km}$. $/ \mathrm{sec}$. towards R.A. $18 \mathrm{~h}$., Dec. $+30^{\circ}$ relative to the nearby stars; a few other necessary corrections are also referred to. Included in the list are the stars the space velocities of which, relative to the local standard of rest, exceed $60 \mathrm{~km}$. $/ \mathrm{sec}$. as well as stars of which only one velocity component, which exceeds $50 \mathrm{~km}$./ sec., is known. In addition, stars the uncorrected proper motion of which exceeds $0 \cdot 5^{\prime \prime}$ annually and for which no further information is yet available are included. Globular clusters, planetary nebulæ and $R R$ Lyr. variables, which obviously belong to population II, have been omitted, and reference is made to a number of other limitations.

Of the 1,315 stars listed proper motions were available for 97 per cent, Draper spectral types for 59 per cent, reliable trigonometrical parallaxes, that is, not less than $0.01^{\prime \prime}$, for 49 per cent, radial velocities for 33 per cent, and complete information for the space velocities only 18 per cent. An unexpected feature was the presence of $37 B$ stars, which are usually considered to form part of the Population I disk system in our Galaxy. It is pointed out, however, that in many cases there are large differences between the radial velocities measured from spectroscopic plates of the same star on different dates, which may indicate that some at least of these stars are undetected binaries with large ranges in velocity relative to the Sun: in nearly every case the parallax and tangential velocity component are unknown.

It is pointed out that new data concerning stars of high velocity will be available, as southern observatories have now many observational programmes under way, and reference is made to the work in progress at a number of these observatories, including the Cape, La Plata, Cordoba, Sydney, and the YaleColumbia Southern Station, now located on Mount Stromlo, Canberra. A few new radial velocities for bright stars have been determined from Cassegrain spectra (36 A./mm.) at $H_{\gamma}$ taken with the Mount Stromlo 30-in. reflector. Classification on the $M K$ system for these and for faint stars with Newtonian spectra $(90 \mathrm{~A} . / \mathrm{mm}$.) from the 74 -in. reflector is in progress. Forty suspected subdwarfs are included in the current observing list.

\title{
ADULT EDUCATION IN WALES
}

T HE report of the Universities Council for Adult Education for $1956-57 *$ is chiefly devoted to a survey of adult education in Wales.

For the purposes of extra-mural work the Principality consists of four college areas (Aberystwyth, Bangor, Cardiff and Swansea), and there are a North Wales District and a South Wales District of the Workers' Educational Association. All provision and administration of extra-mural work is carried out by the four university colleges, the areas of which differ from one another in a variety of ways. The Aberyst. wyth area is entire rural. The Bangor area is also rural for the most part, but it comprises in addition the industrial districts of Flintshire and Wrexham. The Cardiff and Swansea areas are predominantly urban and industrial.

The two-and-a-half million people of Wales are shared unequally between the four areas. Half of them are in the Cardiff area, while Aberystwyth serves a population of about 300,000 scattered over an area which covers almost half of the Principality.

The development of extra-mural work has also varied from area to area. After some tentative beginnings before the First World War, Aberystwyth appointed a director of extra-mural studies in 1920 and, with a small nucleus of full-time tutors, an extra-mural department came into existence. Workers' Educational Association work in the area has not been inconsiderable, but, unaffected by industry, the country folk of this area have not responded so readily to the appeal of an association of workers as have the inhabitants of the other college areas.

The course of events in the other three colleges has been quite different. A South Wales District of the Workers' Educational Association was formed in 1907. This was reconstituted as a Welsh District in 1910 and served the Principality as a whole until the

- Universities Council for Adult Education. Report on the Year 1956-1957. Pp. 27. (Bristol: W. E. Salt, Hon. Secretary and establishment of a North Wales District in 1925. University teachers took a leading part as pioneers for the Association, and throughout the inter-war period the actual organization of extra-mural work in South Wales was conducted largely through the Workers' Educational Association District. Departments of extra-mural studies can scarcely be said to have existed at Cardiff and Swansea until, at the end of the Second World War, the senior staff tutor was appointed secretary of the Swansea joint committee and a tutor in charge of extra-mural classes was appointed at Cardiff. There are still no directors at these two Colleges, though such appointments are contemplated in the present quinquennium.

At Bangor the alliance between College and the Workers' Educational Association was closer still, and the extra-mural work was administered to a considerable extent through the Association's district officer.

Each responsible body has had its own particular story of successes and difficulties. The voluntary bodies in South Wales expanded their work in a spectacular way during the industrial depression of the nineteen-thirties, when a considerable amount of money from the Carnegie Trust was made available to them. In the post-war period, on the other hand, the programmes of these voluntary organizations have dwindled to little more than half their former size, while those of the extra-mural departments of Cardiff and Swansea have grown apace. A great deal of pioneer work was done by the Aberystwyth department during the war years, and although the high figures reached then have not been fully maintained in more recent years, the present volume of work is at least twice what it was before the War. In the Bangor area there has been a striking expansion of Workers' Educational Association classes since the War and an appreciable increase in the classes conducted by the extra-mural department. 
Aberystwyth was the first to break away from the customary restriction of extra-mural work to tutorial and sessional classes, but, since the War, Cardiff has also been conducting an appreciable number of terminal and short courses, while Swansea has recently embarked upon a considerable programme of short extension courses. Apart from the addition of a few short extension courses, Bangor still limits itself to tutorial and sessional courses.

The Adult Education College established at Harlech in 1927 had thirty-nine students in residence for the session 1956-57, and fourteen others attended for a term or two. Almost all the sessional students were drawn from within the Principality, and about half of them were manual workers. But Coleg Harlech has always endeavoured to bring its Welsh students into contact with those of other nations, and this year most of its terminal students and one or two of its sessional students came from such countries as Austria, Hungary, Germany, Denmark, Jamaica and the United States.

Whereas the intensity in industrial South Wales is only slightly more than the average for England, class units in the predominantly rural areas of Aberystwyth and Bangor are three times as numerous as they are in England in relation to population. This is as true of tutorial and sessional classes as it is of other kinds of work.
The subjects of study do not differ fundamentally from those conducted by the other extra-mural departments of the United Kingdom, except that Welsh history predominates over other kinds of history, and Welsh literature over other literatures. Although conditions have changed in recent years, the persistence of old interests is revealed by such facts as that the physical and biological sciences are completely overwhelmed by the humanities, that courses on religious subjects figure about twice as prominently as they do in England, and that there are relatively few courses in the visual arts.

One of the major problems is that of finding sufficient part-time tutors who are really qualified for university work, and this is particularly acute in the rural areas. Each College has five full-time tutors, and these, together with members of the intra-mural staffs, take a third of the classes. In the Aberystwyth and Bangor areas it is often difficult to take full advantage of the teaching staffs of the colleges because most classes within a radius of forty miles from the college centre are conducted in Welsh, a language which three-quarters of the intra-mural staffs do not understand. Each college is obliged to depend upon part-time tutors-lecturers in training colleges and theological colleges, school teachers and ministers of religion-for the bulk of the teaching. The need for a substantial expansion in full-time staffs remains.

\title{
INFLUENCE OF CERTAIN INORGANIC IONS ON THE HATCHING OF THE POTATO ROOT EELWORM, HETERODERA ROSTOCHIENSIS WOLLENWEBER
}

\author{
By Dr. C. ELLENBY and A. B. GILBERT \\ Department of Zoology, King's College (University of Durham), Newcastle upon Tyne
}

\section{$\mathrm{P}$} REVIOUS studies on the influence of salts on the hatching and emergence of larvæ of plant parasitic nematodes have approached the problem largely from the point of view of their possible osmotic effect ${ }^{1,2}$. However, the demonstration that the hatching-factor of the potato root eelworm possesses cardiotonic properties ${ }^{3}$ suggested that the nature of the ions might be of importance. As already briefly announced ${ }^{4}$, this we have found to be the case.

After a preliminary soaking in distilled water, cysts have been stimulated with solutions containing chlorides of sodium, potassium, calcium and magnesium, singly or in various combinations; each solution also contained a quantity of a concentrated hatching-factor preparation free from inorganic material, at a strength $1 / 5$ of its optimum to give scope for increased or decreased hatching. A singlecyst technique was used ${ }^{5}$ and a logarithmic transformation for statistical analyses ${ }^{6}$. In general, we have found that chlorides of the monovalent ions had a depressing effect, that is, hatching was lower than in the hatching factor alone; with the chlorides of the divalent ions hatching was higher. There was also some evidence of antagonism. No emergence took place in the salt solutions without hatching factor.
In most of our experiments, all salt solutions have been equivalent osmotically to $2 \mathrm{mM}$ potassium chloride, so that it has always been possible to compare the different metallic ions independently of any osmotic effect. But in some experiments, a series of different concentrations has been employed, always so that it was possible to compare iso-osmotic solutions of the different salts. In some cases, we have controlled the possible influence of osmotic factors on the performance of the hatching factor alone by the addition of an appropriate quantity of glycerol.

Particular attention has been paid to potassium and calcium ions, in view of their known effect on heart action. The results of a series of experiments are summarized in Fig. 1. Although carried out at different times during 1957, the experiments were sufficiently similar to justify combining their results for purposes of presentation, and, in the diagram, each point is a mean value based on a number of experiments. Most of the experiments were carried out at concentrations equivalent to 2 and to $0.2 \mathrm{mM}$ potassium chloride, the values for higher and lower concentrations being based on fewer experiments. The line representing hatching factor alone is based on nine lots of cysts in five separate experiments, four with hatching factor alone, and five with glycerol added to bring them to various concentrations 